
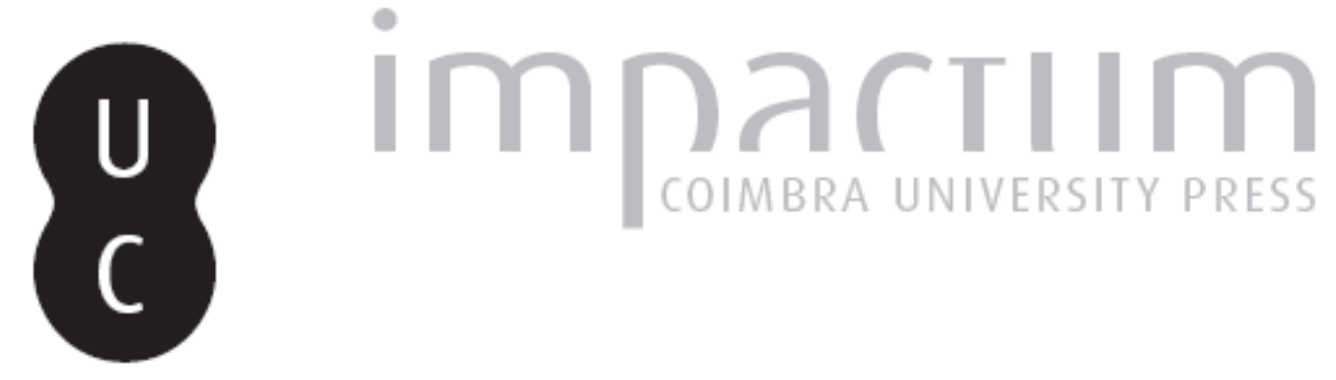

\title{
[Recensão a] Edmondo De Amicis, Constantinopla, prefácio de Umberto Eco, tradução de Margarida Periquito
}

\author{
Autor(es): Boscaglia, Fabrizio
}

Publicado por: Imprensa da Universidade de Coimbra

URL persistente:

URI:http://hdl.handle.net/10316.2/45647

DOI:

DOI:https://doi.org/10.14195/0870-8584_13_14

Accessed : $\quad$ 26-Apr-2023 09:17:37

A navegação consulta e descarregamento dos títulos inseridos nas Bibliotecas Digitais UC Digitalis, UC Pombalina e UC Impactum, pressupõem a aceitação plena e sem reservas dos Termos e Condições de Uso destas Bibliotecas Digitais, disponíveis em https://digitalis.uc.pt/pt-pt/termos.

Conforme exposto nos referidos Termos e Condições de Uso, o descarregamento de títulos de acesso restrito requer uma licença válida de autorização devendo o utilizador aceder ao(s) documento(s) a partir de um endereço de IP da instituição detentora da supramencionada licença.

Ao utilizador é apenas permitido o descarregamento para uso pessoal, pelo que o emprego do(s) título(s) descarregado(s) para outro fim, designadamente comercial, carece de autorização do respetivo autor ou editor da obra.

Na medida em que todas as obras da UC Digitalis se encontram protegidas pelo Código do Direito de Autor e Direitos Conexos e demais legislação aplicável, toda a cópia, parcial ou total, deste documento, nos casos em que é legalmente admitida, deverá conter ou fazer-se acompanhar por este aviso.

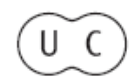




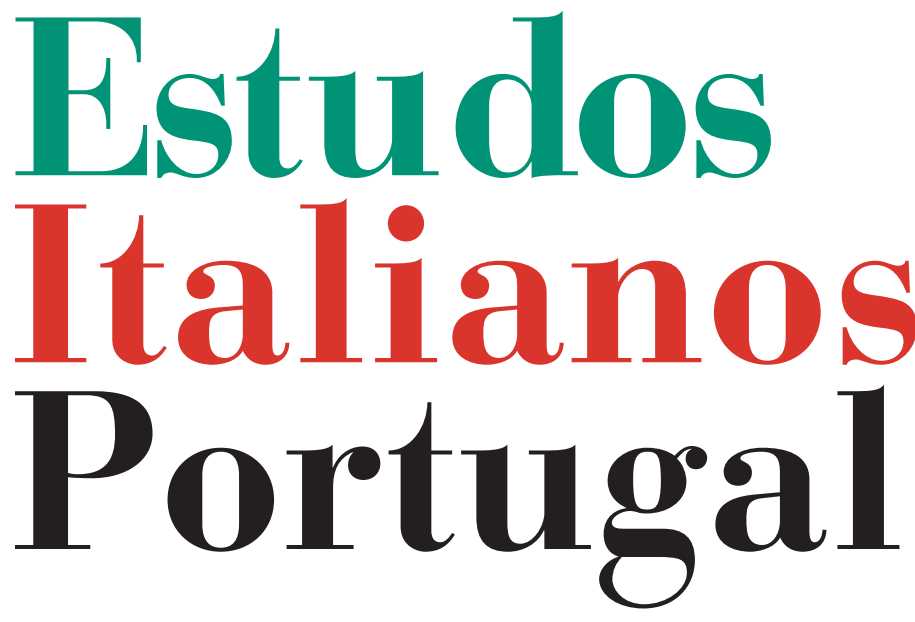

Instituto

Italiano

de Cultura

de Lisboa

Nova Série

$\mathrm{N}^{\mathbf{0}} 13$

2018 
resto una ribellione contro quel discorso economico e tetragono che viene calato dalle alte sfere dell'Eurolandia come inappellabile verità - trova un'eco nella poesia finale del volume, "Com todas as palavras", in cui Alegre riassume in una sorta di breve arte poetica il suo pensiero su quello che deve essere davvero la poesia. L'edizione italiana, che è eccellente, come era naturale attendersi, considerando chi la ha curata, avrebbe forse potuto presentare qualche altra nota, ne contiene solo una e molto pertinente sulla Nau Catrineta. Al lettore italiano, che in genere è poco informato sulla storia e la cultura portoghese, potranno forse sfuggire le allusioni e i rimandi al passato storico, culturale e letterario del Portogallo che rappresentano uno degli stilemi del linguaggio poetico di Manuel Alegre. Gianluca Miraglia

Edmondo De Amicis, Constantinopla, prefácio de Umberto Eco, tradução de Margarida Periquito, Lisboa, Tinta-da-China, 2017, 495 pp.

A coleção de Literatura de Viagem da editora Tinta-da-china enriquece-se com mais um título "oriental". Após Caderno afegão de Alexandra Lucas Coelho
(2009), Cartas persas de Montesquieu (2015) e outras obras, eis que vem a ser publicado Constantinopla de Edmondo De Amicis (1846-1908), relato de viagem à capital turco-otomana, publicado em 1877. A tradução é de Margarida Periquito, cujo trabalho permite acrescentar mais um autor italiano, após os de Alberto Moravia e Tiziano Terzani, à rica coleção dirigida por Carlos Vaz Marques.

O nome de Edmondo De Amicis é famosíssimo em Itália e tem sido indissoluvelmente associado à sua obra mais lida, o romance Coração (Cuore, 1886), espécie de catequese laica para jovens, pilar do imaginário moral(ista) daquela Itália contemporânea, vinda à luz aquando da sua unificação, datada de 1861. Até pelo menos à década de 1990, referir-se a "il libro Cuore" correspondia a utilizar uma expressão-mote que quase cada italiano, tivesse ou não lido a obra, logo associava aos bons sentimentos e virtuosos comportamentos dos valente rapazes narrados em Coração, alunos de uma escola primária italiana, jovens patriotas no início do período unitário, imaculados ícones de um processo que, entre outras transformaçōes, substituía os valores católicos pelo ideário laicista e patriótico do Risorgimento. 
De Amicis, jornalista, escritor, militar e maçon, é dos autores que mais têm deixado um marco neste processo, tendo escrito muitas vezes mais para o povo do que para as elites, incidindo numa narrativa moldada pela sua militância e consubstanciada com frequência numa sensibilidade e num estilo literários de teor jornalístico e de tom leve, educativo e descritivo.

\section{Constantinopla (Costantinopoli),} do ponto de vista estilístico, não apresenta exceção, sendo caraterizado por uma escrita de reportagem cativante, dirigida ao grande público. Apesar de muito menos conhecido do que Coração, o relato da viagem de De Amicis à capital do outrora Império Otomano (1299-1922) é um livro importante na produção do autor, sendo uma das obras mais elogiadas e criticadas entre as que a literatura mundial consagrou à cidade que a partir da década de 1930 passou a chamar-se Istanbul, hoje capital da Turquia. Constantinopla insere-se, de facto, numa espécie de linhagem de livros sobre a "segunda Roma”, entre as quais Constantinople de Théophile Gautier (1852) e Istanbul do escritor turco Orham Pamuk (2003), que aliás considera o livro de De Amicis como o melhor volume dedicado à cidade da qual é natural. Em Portugal, o livro não passou despercebido após a sua publicação, merecendo uma primeira tradução, em 1889, por Manuel Pinheiro Chagas.

O valor estético que Pamuk reconhece ao diário do autor italiano assenta nas notáveis descrições que animam os cerca de setenta parágrafos, cada um dedicado por De Amicis a retratar zonas, figuras, monumentos e comunidades da cidade. Trata-se, inclusivamente, de um roteiro, ao mesmo tempo turístico, literário, históricocultural e enciclopédico. O leitor, desde as primeiras páginas que descrevem a chegada marítima do autor ao Bósforo, é magistralmente levado a descobrir as maravilhas do Oriente por um cicerone de eleição, que não negligencia o tom fascinado e o olhar erudito e irónico sobre a história, os costumes e a população da cidade.

Trata-se de descrições, tons e rasgos de erudição tipicamente orientalistas do século XIX. De Amicis descreve dervixes e bazares, vielas e minaretes, mesquitas e cúpulas bizantinas, eunucos e haréns, fabulosas sensualidades e enganos cruéis... O imaginário orientalista protagoniza a narração, numa leitura ágil, oferecendo um precioso testemunho pessoal da capital otomana no período final da decadência do Império. O "grande doente da Europa” já não era, naqueles tempos, o pesadelo turco que ti- 
nha assustado o resto do Velho Continente, desde pelo menos a tomada da própria Constantinopla aos cristãos bizantinos em 1453; nem continuava a ser, perante o avanço das potências coloniais nas suas áreas de influência, o gigante geopolítico dos séculos idos, que tinha competido com o Império Português (outro moribundo finissecular) e onde os italianos (os "levantinos") se tinham instalado em colónias às quais o patriota De Amicis dedica várias passagens.

Contudo, a magnificência de Constantinopla não se encontra diminuída e emerge aliás de forma notável no livro, inclusivamente no que respeita ao multiculturalismo de convivência entre religiōes e etnias, implementado pelos Sultôes muçulmanos. Istanbul é, de facto, cidade cujas pontes juntam e separam Europa e Ásia, Cristandade e Islão, Passado e Futuro, Ocidente e Oriente, os "nós" e os "eles" de uma narrativa histórica de choques e diálogos, que continua atualíssima e que, do lado de De Amicis, sofria o forte influxo do colonialismo. Interessa-nos, pois, a leitura histórico-cultural, que contribui para fazer desta tradução um evento editorial digno de menção, em tempos em que a questão da inclusão ou exclusão da Turquia na União Europeia agita a Europa, ressuscitando os fantas- mas orientalistas. Em De Amicis encontramos o clássico orientalismo, consubstanciado numa rígida distinção entre "nós" e "eles" (o vago Oriente), à qual se junta a referida representação sensual, misteriosa, fatalista, subdesenvolvida e fanática do próprio Oriente e da(s) sua(s) crença(s), neste caso do Islão.

É, de facto, no juntar-se de laicismo e orientalismo que as páginas de Constantinopla chamam a uma leitura crítica. É o caso dos parágrafos dedicados a "Maomé" e ao "Ramadão": no primeiro, De Amicis reinventa a história do Islão como religião e civilização fundadas na luxúria, que segundo o autor seria a causa da decadência de todo o Oriente (curiosamente, o iluminista e laicista De Amicis parece herdar este estereótipo fantástico da chamada "Idade das Trevas" das Cruzadas); no segundo, talvez haja uma invenção ainda mais patente, chegando o autor a afirmar que durante o mês do jejum islâmico, praticado da madrugada ao início do pôr do sol, os muçulmanos turcos quebrem a abstinência diária da comida só ao fim do próprio pôr-do-sol, num improvável masoquismo que perfeitamente se enquadra no referido paradigma orientalista (perguntamo-nos, pois, se a própria eventualidade de ser conquistado e colonizado não 
seria, para tal oriental masoquista, um gozo!).

Apesar de ter havido, no mesmo período, europeus que elogiavam a civilização do Islão e o seu Profeta - entre eles Friedrich Nietzsche e Antero de Quental - não se estranha que, dadas as circunstâncias históricas e culturais, De Amicis descrevesse o Islão e o chamado Oriente com um olhar ideológico e de preconceito, tal como tinha feito no seu anterior diário de viagem dedicado a Marrocos (Marocco, 1873). A este respeito repare-se que, segundo Umberto Eco, autor do prefácio de Constantinopla, a "peregrinação" cultural de De Amicis ao "Santuário do Diferente" é tornada "patética" pelas próprias matrizes histórico-culturais envolvidas.

Por todas estas razōes, destacamos o valor científico da publicação em Portugal de Constantinopla, sobretudo pelas possibilidades críticas que a sua leitura oferece, para o estudo - com um olhar atento aos desafios da contemporaneidade das condições e dos contextos geopolíticos, históricos e culturais da sua composição, publicação, receção e reedição. FABRiZio BosCaGlia

La letteratura portoghese. I testi e le idee, a cura di Roberto Vec- chi; Vincenzo Russo, Firenze, Le Monnier, 2017, 642 pp.

Qualsiasi tentativo di ricostruire la storiografia letteraria portoghese implica inevitabilmente il confronto con un intricato labirinto che assorbe dal passato mitico, più ancora che da quello storico, il proprio sostrato essenziale. Intorno a questa fondamentale considerazione si articola l'importante volume antologico curato da Roberto Vecchi e Vincenzo Russo, dedicato - non a caso - a Eduardo Lourenço, a cui peraltro si deve l'illuminante (e ormai storica) riflessione intorno al concetto di "labirinto della saudade", topos critico tramite cui, analizzando i processi dell'immaginazione e dell'arte, si tenta di spiegare e di rendere coerente un "complesso storico di incompiutezza". Lo stesso Lourenço, in un recente articolo pubblicato sul Jornal de Letras ( $\mathrm{n}^{\circ} 258$, luglio 2018), invitava a riflettere sulla natura e sulla qualità attuali della presenza letteraria portoghese al di fuori dei confini nazionali e sulle relazioni tra Stato e cultura (quindi su maggiore o minore "cultura della rappresentazione di Stato" nel contesto "ricevente") che si trova alla base di tale presenza.

La letteratura portoghese. I testi e le idee si pone - come affermano gli stessi curatori - come "cerniera" 